\title{
Improving predictions of the effects of extreme events, land use, and climate change on the hydrology of watersheds in the Philippines
}

\author{
Rubianca Benavidez $^{1}$, Bethanna Jackson ${ }^{1}$, Deborah Maxwell ${ }^{1}$, and Enrico Paringit ${ }^{2}$ \\ ${ }^{1}$ School of Geography, Environment and Earth Sciences, Victoria University of Wellington, Wellington, 6012, \\ New Zealand \\ ${ }^{2}$ Disaster Risk and Exposure Assessment for Mitigation Program, Quezon City, 1101, Philippines \\ Correspondence to: Rubianca Benavidez (rubianca.benavidez@vuw.ac.nz)
}

Published: 12 May 2016

\begin{abstract}
Due to its location within the typhoon belt, the Philippines is vulnerable to tropical cyclones that can cause destructive floods. Climate change is likely to exacerbate these risks through increases in tropical cyclone frequency and intensity. To protect populations and infrastructure, disaster risk management in the Philippines focuses on real-time flood forecasting and structural measures such as dikes and retaining walls. Real-time flood forecasting in the Philippines mostly utilises two models from the Hydrologic Engineering Center (HEC): the Hydrologic Modeling System (HMS) for watershed modelling, and the River Analysis System (RAS) for inundation modelling. This research focuses on using non-structural measures for flood mitigation, such as changing land use management or watershed rehabilitation. This is being done by parameterising and applying the Land Utilisation and Capability Indicator (LUCI) model to the Cagayan de Oro watershed $\left(1400 \mathrm{~km}^{2}\right)$ in southern Philippines. The LUCI model is capable of identifying areas providing ecosystem services such as flood mitigation and agricultural productivity, and analysing trade-offs between services. It can also assess whether management interventions could enhance or degrade ecosystem services at fine spatial scales. The LUCI model was used to identify areas within the watershed that are providing flood mitigating services and areas that would benefit from management interventions. For the preliminary comparison, LUCI and HEC-HMS were run under the same scenario: baseline land use and the extreme rainfall event of Typhoon Bopha. The hydrographs from both models were then input to HEC-RAS to produce inundation maps. The novelty of this research is two-fold: (1) this type of ecosystem service modelling has not been carried out in the Cagayan de Oro watershed; and (2) this is the first application of the LUCI model in the Philippines. Since this research is still ongoing, the results presented in this paper are preliminary. As the land use and soil parameterisation for this watershed are refined and more scenarios are run through the model, more robust comparisons can be made between the hydrographs produced by LUCI and HEC-HMS and how those differences affect the inundation map produced by HEC-RAS.
\end{abstract}

\section{Introduction}

The Philippines is regularly struck by tropical cyclones. An annual average of twenty enter the region, of which about nine make landfall and often cause destructive floods (Lasco et al., 2009). In 2011, Typhoon Washi caused heavy flooding and destruction in the Cagayan de Oro region, leaving 1268 casualties and PHP 2 billion in damages ( USD 46 million in 2011) (National Disaster Risk Reduction Man- agement Council, 2012a). Since the Philippines is located within the typhoon belt, the country is vulnerable to the effects of climate change due to possible increases in typhoon frequency and intensity (Intergovernmental Panel on Climate Change, 2012). The vulnerability of the country to tropical cyclones and climate change underscores the need for more proactive disaster risk management, which to date is mainly carried out through flood forecasting and structural flood protection projects. 


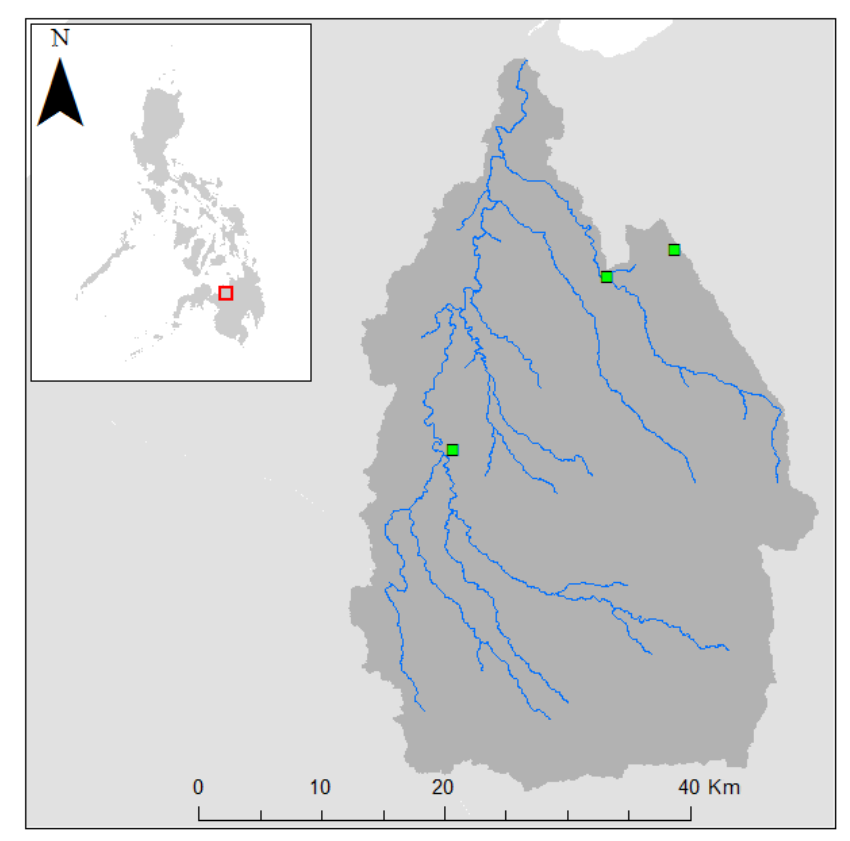

Figure 1. The Cagayan de Oro watershed and rain gauges relative to the Philippines.

The official programme of disaster mitigation in the Philippines is Project NOAH (Nationwide Operational Assessment of Hazards). This programme mainly uses two models from the United States Hydrologic Engineering Center (HEC): the Hydrologic Modeling System (HMS) for watershed modelling, and the River Analysis System (RAS) for inundation modelling (Brunner, 2010; Scharffenberg, 2013). Project NOAH uses these models for real-time flood forecasting and produces flood hazard maps available on a public website (Santillan et al., 2013). These models have also been used to analyse the watershed response to extreme events and changing land use, estimating peak flow and occurrence time, and modelling the floodplain inundation (Mabao and Cabahug, 2014; Santillan et al., 2011).

Although these models can assist in decision-making through running different land use scenarios, they do not identify areas to target for potential management interventions. Reforestation activities in the Cagayan de Oro (CDO) watershed (Fig. 1) tend to occur in easily-accessible areas, which may not be the areas that would optimally benefit from management interventions (Center for Environmental Studies and Management, 2014). This research applies a model developed to aid in scientifically-sound decision-making regarding land management: the Land Utilisation and Capability Indicator (LUCI). This is being used to identify areas providing existing ecosystem services, areas where management interventions can enhance or degrade ecosystem services, trade-offs between services, and impacts of changing land cover (Jackson et al., 2013). This type of ecosystem services modelling has not been carried out in the Philippines to

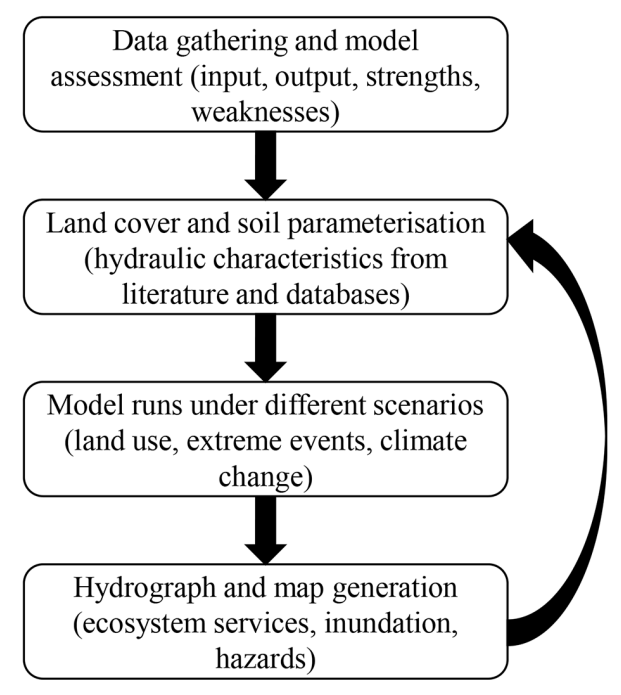

Figure 2. Methodology of the study.

date, and the LUCI model can aid in more sustainable land management in the CDO watershed. This research is also the first application of LUCI in a tropical catchment, which will allow testing of how well the model is able to represent hydrological processes in such regions.

This research is still on-going, so the results presented in this paper are preliminary. As the soil and land use parameterisation is refined, the models will be run under more scenarios of changing land use, extreme events, and extreme events affected by climate change. The main aims of this research are: (1) to apply the LUCI model to the Cagayan de Oro catchment to help identify priority areas for land management; (2) assess how the LUCI model fits into the existing disaster risk management framework in the Philippines, and (3) assess how the hydrological response of the watershed changes under different scenarios of land use, extreme events, and climate change.

\section{Methodology}

An overview of the methodology is shown in Fig. 2. First, thematic datasets of land cover, soil, and topography were gathered from various sources and at different scales (local, national, global). Next, land cover and soil parameterisation for the LUCI model was carried out through correlating local soil names with the United States Department of Agriculture (USDA) soil taxonomy, and using the Soil Water Characteristics (SWC) model to estimate the soils' hydraulic characteristics (Saxton and Rawls, 2006). The watershed and floodplain model in HMS and RAS were made and parameterised by the Disaster Risk and Exposure Assessment for Mitigation Program (DREAM) (2015).

In LUCI, the land cover and soil dataset was used to produce ecosystem services maps in order to identify which ar- 


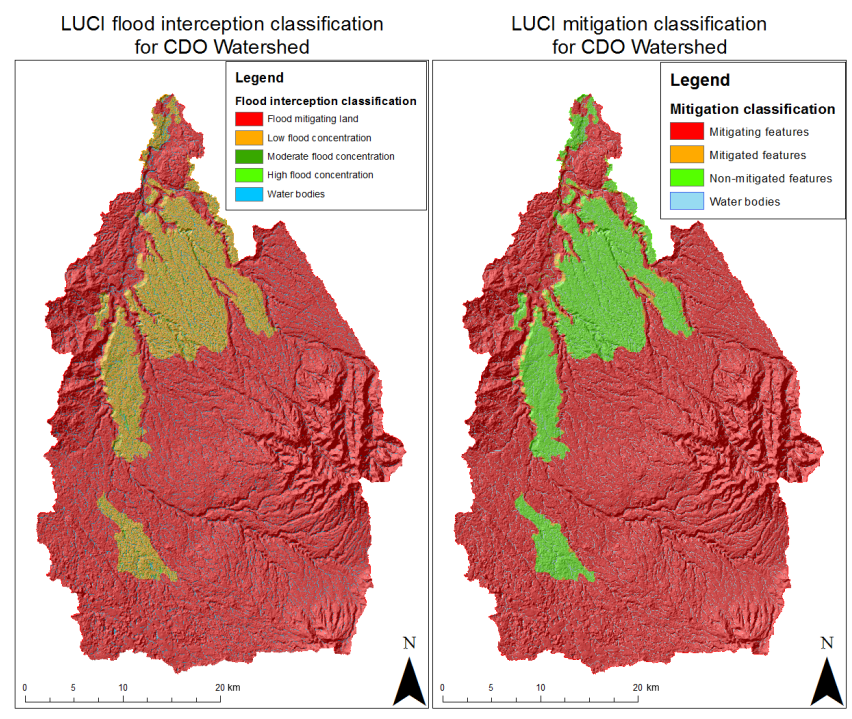

Figure 3. Flood interception and mitigation classification for the $\mathrm{CDO}$ watershed.

eas could be targeted for management interventions to improve flood mitigation.

Although this study aims to run the models under different scenarios, this paper presents one extreme event scenario: Typhoon Bopha (local name: Pablo). In December 2012, Typhoon Bopha hit the region and caused a total of $1067 \mathrm{ca}-$ sualties and estimated PHP 36 billion in damages ( USD 870 million in 2012) (NDRRMC, 2012b). In this scenario, the land cover and soil dataset was the same dataset used to construct the current flood forecasting model for the CDO watershed. The rainfall data was taken from three different rain gauges: Bubunawan, Libona, and Talakag, and was provided by the DREAM Program (2015).Using the Typhoon Bopha rainfall data, rainfall-runoff modelling was performed in both LUCI and HEC-HMS to produce hydrographs for comparison. Both hydrographs were then used as input into HEC-RAS for inundation modelling, and the resulting inundation maps were prepared in ArcMap 10.3.1.

\section{Results and discussion}

This section presents the preliminary results of this research: the initial LUCI results for the CDO watershed, the hydrographs from LUCI and HEC-HMS, and the resulting inundation maps from HEC-RAS.

\subsection{Initial LUCI results}

The LUCI model is used to assess the existing and potential impacts of changes in land use management on the following ecosystem services: habitat connectivity, flood mitigation, erosion/sediment delivery, carbon sequestration, and agricultural productivity (Jackson et al., 2013). The flood

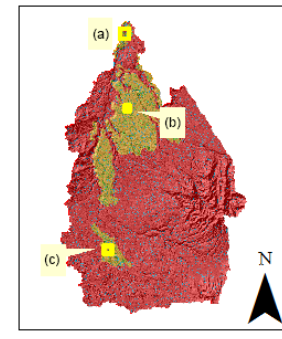

(a)
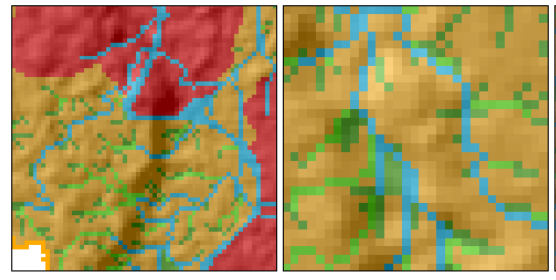

Figure 4. A zoom of some areas of the watershed to show flood interception at a smaller scale.

mitigation service is the main focus for this paper, but this LUCI application aims to model the rest of the ecosystem services and trade-offs as the land cover and soil parameterisation is further refined. The model makes use of a "traffic light" system for its output maps: red means to stop or that changes in land use may degrade the ecosystem service, yellow/orange means that careful management interventions can be carried out, and green areas are priority areas since management interventions have the potential to improve the service (Jackson et al., 2013).

Figure 3 shows the initial LUCI results for the study site for the ecosystem service of flood mitigation. For the flood interception map, red areas are those providing good flood mitigation and any land management changes are likely to adversely affect its capability for flood mitigation. Conversely, green areas are areas of high and moderate flood concentration and can be targeted for management interventions such as rehabilitation or reforestation. The yellow/orange areas of flood interception are areas of low flood concentration, but can be targeted for management interventions since the LUCI algorithm identifies them as non-mitigated features.

At the watershed scale, the green areas or areas that are possible targets for management interventions are not immediately obvious. Figure 4 shows that the model has identified areas for management interventions at the smaller scale, identifying areas where flow accumulates before reaches streams and rivers. Based on the initial LUCI results, smallscale and targeted management efforts have the potential to be more useful to improving flood mitigation services than choosing large portions of land for reforestation. This is important because limited funding for watershed rehabilitation was one of the problems identified in the development of the watershed management plan, so a smaller-scale but more targeted approach may be more beneficial (CESM, 2014). As 


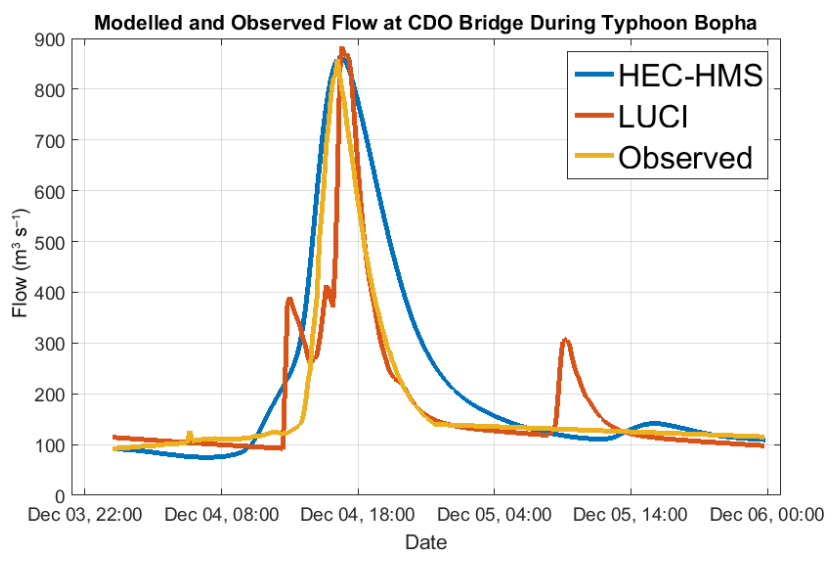

Figure 5. The modelled hydrographs from HEC-HMS and LUCI compared to the observed flow during Typhoon Bopha.

the soil and land cover parameterisation in LUCI is refined and iterative model runs are done, this application can produce a much clearer picture of priority rehabilitation areas in the watershed and be used to assess the potential result of the local government's plans for rehabilitation or utilisation.

\subsection{Typhoon Bopha results: LUCI, HEC-HMS, and HEC-RAS}

Under the scenario of Typhoon Bopha, the hydrographs of HEC-HMS and LUCI compare reasonably well with the observed flow at the Cagayan de Oro Bridge (Fig. 5). The peak flows were: $864679 \mathrm{~m}^{3} \mathrm{~s}^{-1}$ (HEC-HMS), $883963 \mathrm{~m}^{3} \mathrm{~s}^{-1}$ (LUCI), and $858.3 \mathrm{~m}^{3} \mathrm{~s}^{-1}$ (observed). Both hydrographs from LUCI and HEC-HMS show a similar peak flow volume and occurrence time, as well as a smaller peak after the main flood event. The LUCI hydrograph shows a flashier watershed response and a later peak flow occurrence time compared to the HEC-HMS hydrograph. However, the LUCI hydrograph shows a more similar falling limb when compared to the observed flow. Another similarity between the LUCI hydrograph and the observed flow is the flood volume, as LUCI is able to capture the more abrupt rise and fall of the flood peak, while the HEC-HMS hydrograph shows a more gradual rise and fall, implying an over-prediction of the flood volume.

When both hydrographs are run through HEC-RAS, the produced inundation maps are relatively similar (Fig. 6). The maximum inundation depths were: 4.82 (HEC-HMS) and $4.63 \mathrm{~m}$ (LUCI). Although the inundation extent using the HEC-HMS hydrograph is larger compared to the inundation extent produced by the LUCI hydrograph, the inundation occurs in the same areas: at the mouth of the river and areas where the river meanders. Based on this initial comparison, LUCI is able to predict the watershed's response with similar performance to the HEC-HMS model, and the inundation

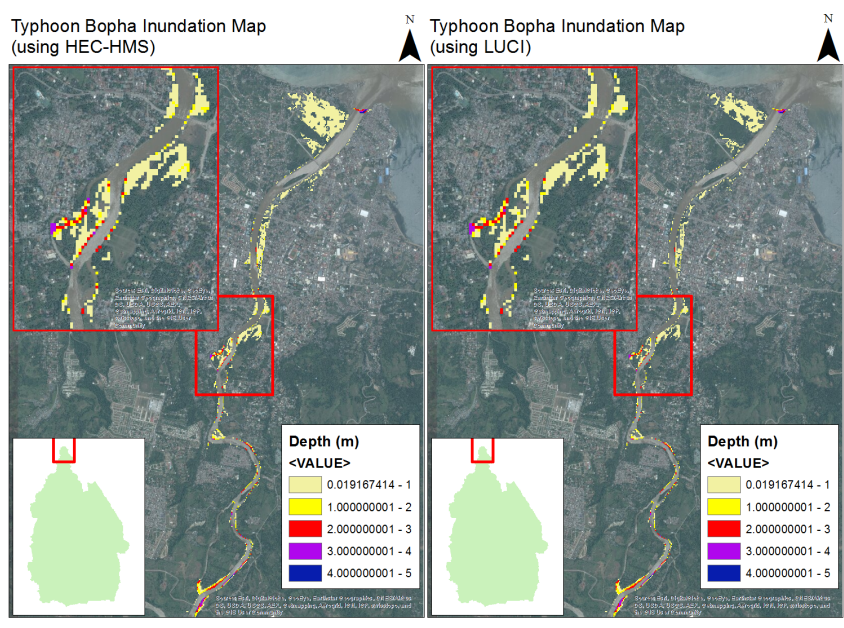

Figure 6. Inundation maps produced in HEC-RAS using the HECHMS hydrograph and the LUCI hydrograph, with the inset showing the flood water encroaching on the river banks and buildings.

map based on the LUCI hydrograph is also similar to the inundation map based on the HEC-HMS hydrograph.

LUCI, HEC-HMS, and HEC-RAS can be used in combination to complement each other's strengths and weaknesses. For example, LUCI has the capability to go down to significantly finer spatial scales than HEC-HMS. Given its fine resolution, LUCI can run reasonably efficiently at the watershed scale, which has advantages for flood forecasting and uncertainty estimation. However, HEC-HMS takes less processing time to run over the entire watershed. The current configuration of HEC-HMS used by the disaster risk programme uses the curve number method to determine the subbasin runoff. This method uses one composite number to represent the different soil and land use combinations present within a sub-basin (Scharffenberg, 2013). While this allows the programme to take less processing time, it cannot capture the explicit spatial configuration of elements within the watershed. This makes it less useful for assisting in decisionmaking regarding land use management. By contrast, the LUCI model uses the soil and land use data to account for the storage and permeability of the different elements within the watershed, which allows the model to perform watershed modelling and represent possible management impacts at fine spatial scales (Jackson et al., 2013). This method allows LUCI to take spatial configuration into account and identify areas that would either benefit from management interventions, or where changing land use would degrade an ecosystem service. This would make the LUCI model more useful to stakeholders and local government making management decisions, or choosing areas for rehabilitation or development.

The models address different areas of disaster risk management: the HEC models for short-term flood forecasting and LUCI for long-term land use planning. The expedience 
of the HEC models allows the DREAM Program to automate the process of watershed modelling and inundation modelling at 10-min intervals to produce maps that are accessible through a public website (Santillan et al., 2013). The HEC models have also been well-applied in the Philippines as this automated system is being used for flood forecasting in eighteen major river basins in the country (Lagmay, 2012). Through running scenarios of local government plans for rehabilitation and development, the LUCI model can complement the existing system by assessing the potential impacts of land use changes, and identifying priority areas for management interventions. By coupling LUCI with HECRAS, the impacts of management decisions can be elucidated through inundation modelling and comparing the resulting maps with maps from the baseline scenarios.

\section{Conclusions and further research}

Given the vulnerability of the Philippines to typhoons and their resulting floods, it is important to invest in proactive measures for disaster risk mitigation. Three of the ways this can be done is through robust hydrological modelling for flood forecasting, structural measures for flood protection, and through making environmentally-sound land management decisions within the watershed. The initial LUCI application in the Cagayan de Oro watershed seeks to address the component of land management decisions through modelling the ecosystem service of flood mitigation in the CDO watershed. The model was able to identify areas to target for management interventions to improve the ecosystem service of flood mitigation. The priority areas are areas before the flow reaches streams and rivers, suggesting that the smallscale targeted rehabilitation approach may be more useful to improving flood mitigation compared to reforesting large areas within the watershed. Under the Typhoon Bopha scenario, LUCI and HEC-HMS produced similar hydrographs in terms of peak flow and occurrence time, and similar inundation maps. The next steps for this research are to refine the soil and land cover parameterisation to produce LUCI maps of the different ecosystem services, identify trade-offs, and to run the model under different land cover scenarios. After that, the rainfall-runoff modelling capability of the LUCI model can be compared with the HEC models to assess how the LUCI model is able to accurately represent watershed hydrological response.

\section{Data availability}

This research used secondary data provided by the DREAM Program (https://dream.upd.edu.ph/).

Acknowledgements. R. Benavidez acknowledges the support and guidance of her supervisors: B. Jackson, D. Maxwell, and E. Paringit. Thanks to the fellow hydrology researchers at the Victoria University of Wellington and the University of the Philippines.
Thanks to the DREAM Program for providing thematic datasets, rainfall datasets, and the basin and floodplain model. Thanks to the Cagayan de Oro City Hall, the Department of Public Works and Highways, the Regional Development Council, the Department of Agriculture, and the Philippine Atmospheric, Geophysical and Astronomical Services Administration for providing datasets and watershed reports.

\section{References}

Brunner, G.: HEC-RAS User's Manual, 2010.

Center for Environmental Studies and Management: Formulation of an Integrated River Basin Management and Development Master Plan for Cagayan de Oro river Basin, San Juan City, Metro Manila, Philippines, 2014.

Disaster Risk and Exposure Assessment for Mitigation Program: HEC-RAS and HEC-HMS Model Parameterised for Cagayan de Oro, Philippines, University of the Philippines Diliman, Quezon, City, 2015.

Intergovernmental Panel on Climate Change: Managing the Risks of Extreme Events and Disasters to Advance Climate Change Adaptation, Cambridge, UK, and New York, USA, 2012.

Jackson, B., Pagella, T., Sinclair, F., Orellana, B., Henshaw, A., Reynolds, B., and Eycott, A.: Polyscape: A GIS mapping framework providing efficient and spatially explicit landscape-scale valuation of multiple ecosystem services, Landscape Urban Plan., 112, 74-88, doi:10.1016/j.landurbplan.2012.12.014, 2013.

Lagmay, A. M. F.: Disseminating near real-time hazards information and flood maps in the Philippines through Web-GIS, DOSTProject NOAH Open-File Reports, 1, 28-36, ISSN 2362-7409, 2012.

Lasco, R. D., Pulhin, F. B., Jaranilla-Sanchez, P. A., Delfino, R. J. P., Gerpacio, R., and Garcia, K.: Mainstreaming adaptation in developing countries: The case of the Philippines, Climate and Development, 1, 130, doi:10.3763/cdev.2009.0009, 2009.

Mabao, K. and Cabahug, R. G.: Assessment and Analysis of the Floodplain of Cagayan De Oro River Basin, Mindanao Journal of Science and Technology, 12, 147-170, 2014.

National Disaster Risk Reduction and Management Council: Final Report on the Effects and Emergency Management re Tropical Storm "SENDONG" (Washi), 2012a.

National Disaster Risk Reduction and Management Council: Update re Effects of Typhoon "PABLO" (Bopha), 2012b.

Santillan, J. R., Makinano, M., and Paringit, E.: Integrated Landsat Image Analysis and Hydrologic Modeling to Detect Impacts of 25-Year Land-Cover Change on Surface Runoff in a Philippine Watershed, Remote Sensing, 3, 1067-1087, doi:10.3390/rs3061067, 2011.

Santillan, J. R., Ramos, R. V., Recamadas, S., David, G., Paringit, E. C., Espanola, N. C., and Alconis, J.: Use of geospatial technologies and numerical modeling to monitor and forecast flooding along Marikina River, Philippines, Proceedings of the 12th SEASC: Geospatial Cooperation Towards a Sustainable Future, 2013.

Saxton, K. E. and Rawls, W. J.: Soil Water Characteristic Estimates by Texture and Organic Matter for Hydrologic Solutions, Soil Sci. Soc. Am. J., 70, 1569, doi:10.2136/sssaj2005.0117, 2006.

Scharffenberg, W. A.: HEC-HMS: User's Manual, Washington, D.C., 2013. 